\title{
Hepatic Stellate Cell Proliferation is an Early Platelet-Derived Growth Factor-Mediated Cellular Event in Rat Cholestatic Liver Injury
}

\author{
Nils Kinnman, Odile Goria, Dominique Wendum, Marie-Claude Gendron, \\ Colette Rey, Raoul Poupon, and Chantal Housset
}

Institut National de la Santé et de la Recherche Médicale U402 (NK, OG, CR, RP, CH), Service d'HépatoGastroentérologie (NK, OG, RP, CH), Service d'AnatomoPathologie, Hôpital Saint-Antoine (DW), Service Commun de Cytométrie en Flux, Institut Jacques Monod (M-CG), Paris; Service des Maladies de l'Appareil Digestif et de la Nutrition, Hôpital Charles Nicolle, Centre Hospitalier Universitaire de Rouen (OG), Rouen, France; Department of Gastroenterology and Hepatology, Karolinska Institutet (NK), Stockholm, Sweden

\begin{abstract}
SUMMARY: After liver injury, hepatic stellate cells (HSC) undergo a pleiotropic response termed "activation" that also occurs in culture models and ultimately leads to the conversion of HSC into myofibroblasts expressing smooth muscle $\alpha$-actin ( $\alpha$-SMA). The onset of HSC proliferation in primary culture coincides with the induction of platelet-derived growth factor receptor- $\beta$ (PDGFR- $\beta$ ) expression, while platelet-derived growth factor (PDGF) is the most potent mitogen for culture-activated HSC. Yet, the mechanisms and the stage of activation required for HSC proliferation in the intact liver are still uncertain. In the present study, we analyzed the proliferative response of HSC to rat cholestatic liver injury and the role of PDGF in this response. After in vivo incorporation of bromodeoxyuridine (BrdU), pure vitamin A-containing HSC were isolated at different time points after bile duct ligation (BDL) or sham operation and were analyzed by means of flow cytometry. The induction of HSC proliferation, as ascertained by BrdU incorporation, occurred between 24 and 48 hours and reached a plateau as soon as 48 hours after BDL. Flow cytometry and immunoblot analyses of HSC indicated that the induction of proliferation in HSC coincided with the up-regulation of PDGFR- $\beta$ protein on their surface but preceded that of $\alpha$-SMA. A dose-dependent inhibition of PDGF-BBinduced HSC proliferation by STI571, a PDGF receptor tyrosine kinase inhibitor, was documented in vitro. Daily intraperitoneal injections of STI571 (20 mg/kg) caused a 60\% reduction in BrdU positive isolated HSC and in the amount of desminimmunoreactive sinusoidal cells on liver tissue sections in 48-hour bile duct-ligated rats. These results indicate that cholestatic liver injury elicits an early proliferative response in HSC that is mainly mediated by PDGF, and which precedes HSC phenotypic conversion into myofibroblasts. (Lab Invest 2001, 81:1709-1716).
\end{abstract}

$F$ ollowing liver injury, hepatic stellate cells (HSC) undergo a pleiotropic response termed "activation" (Friedman, 2000). The entire process ultimately leads to the conversion of a quiescent vitamin A-storing cell into a fibrogenic myofibroblastic cell. The cellular features of activation have been extensively characterized in culture models, because the phenotypic changes identified in the injured liver also occur in culture. Induced gene expression of smooth muscle $\alpha$-actin ( $\alpha$-SMA) is the hallmark of HSC activation both in culture and in the intact liver (Bachem et al, 1993; Maher and McGuire, 1990; Rockey et al,

Received September 24, 2001.

Nils Kinnman and Odile Goria contributed equally to the work.

This work was supported by Institut National de la Santé et de la Recherche Médicale, Paris, France. N. Kinnman was supported by grants from the Swedish Society of Medicine, The Swedish Institute, The Swedish Society of Medical Research, The Jublin Foundation, The Wennergren Foundation, and the French Association vaincre la Mucoviscidose.

Address reprint requests to: Dr. Chantal Housset, INSERM U402, Faculté de Médecine Saint Antoine, 27, rue de Chaligny, 75571 Paris cedex 12, France.E-mail: chantal.housset@st-antoine.inserm.fr
1992). Upon culture activation, HSC also move from a nonproliferative to a highly proliferative state (Bachem et al, 1993; Pinzani et al, 1989; Rockey et al, 1992; Wong et al, 1994). Platelet-derived growth factor (PDGF) has been identified as the most potent polypeptide growth factor able to stimulate the proliferation of culture-activated HSC (Pinzani et al, 1989).

PDGF isoforms are disulphide-bonded dimers of either AA, AB, or BB polypeptide chains. Their effects on target cells are mediated by dimeric transmembrane receptors composed of $\alpha$ and/or $\beta$ subunits with intrinsic protein-tyrosine kinase activity (Heldin and Westermark, 1990). The $\alpha$ subunit binds both the $A$ and the $B$ chain of PDGF with high affinity, whereas the $\beta$ subunit binds the B chain only (Hart et al, 1988; Heldin et al, 1988). Quiescent HSC exhibit constitutive expression of the $\alpha$ subunit but no detectable transcript for the $\beta$ subunit (Wong et al, 1994). Plateletderived growth factor receptor- $\beta$ (PDGFR- $\beta$ ) expression is induced in primary cultures of rat HSC within 3 days after plating, coincident with the onset of cellular proliferation (Wong et al, 1994). PDGF exerts no mitogenic effect on HSC in very early culture (Bachem 
et al, 1993), suggesting that the de novo expression of PDGFR- $\beta$ is a prerequisite for PDGF growth stimulatory action to occur. PDGFR- $\beta$ mRNA is also induced in HSC within hours after bile duct ligation (BDL) or carbon tetrachloride administration (Wong et al, 1994). However, direct evidence that HSC proliferation in vivo is mediated by PDGF is lacking. Moreover, because most of previous in situ studies on cell proliferation (Geerts et al, 1991; Hines et al, 1993) were not designed to discriminate between HSC and other hepatic cells of the fibroblast lineage (Knittel et al, 1999a, 1999b), the stage of activation required for $\mathrm{HSC}$ to undergo proliferation in vivo remains uncertain.

In the present study, proliferation was examined in pure vitamin A-containing HSC isolated from rat liver at early time points after the initiation of liver injury caused by biliary obstruction. The data presented indicate that, after cholestatic liver injury, the induction of a proliferative response in HSC is an early event that is mediated predominantly by PDGF and that precedes HSC phenotypic conversion into myofibroblasts.

\section{Results}

The proliferative response of HSC during initial liver injury was determined after in vivo incorporation of bromodeoxyuridine (BrdU) by the analysis of freshly isolated cells. The cells underwent virtually no influence of a culture environment in this procedure and only highly pure ( $\geq 99 \%$ ) populations of HSC were examined, as ascertained by the detection of their autofluorescent retinoid content (Fig. 1, A and B). Flow cytometry analyses showed that the proportion of HSC incorporating BrdU significantly increased in bile duct-ligated rats (Fig. 2). The increase in BrdU incorporation occurred between 24 and 48 hours and reached a plateau as soon as 48 hours after BDL (Fig. 2). At this initial stage of liver injury, $\alpha$-SMA was undetectable by immunoblot in HSC isolates (Fig. 3, lane 3). Expression at a very low level, as compared with culture-activated myofibroblastic HSC, was detected in HSC isolates 7 days after BDL (Fig. 3, lane 4). These results indicate that the induction of proliferation is a very early event that precedes the complete phenotypic change of HSC into myofibroblasts in vivo.

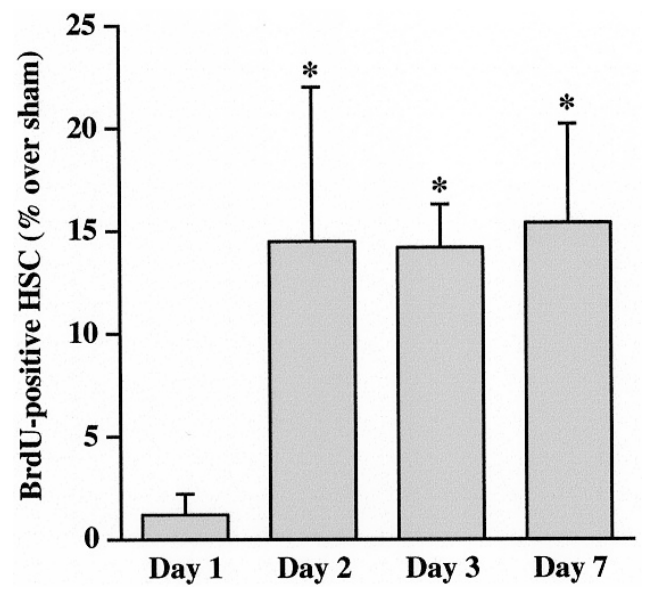

Figure 2.

Induction of HSC proliferation after bile duct ligation (BDL). HSC of high purity $(\geq 99 \%)$, as illustrated in Figure 1, were isolated simultaneously from one bile duct-ligated rat and from one sham-operated rat on postoperative days $1,2,3$, and 7 . One hour before cell isolation, each animal received an intraperitoneal injection of bromodeoxyuridine (BrdU) $(50 \mathrm{mg} / \mathrm{kg})$. BrdU was then immunodetected in freshly isolated HSC by flow cytometry. Results represent the percentage of BrdU-positive cells in bile duct-ligated rats compared with that in sham-operated rats and are the means \pm SEM of three separate experiments. ${ }^{*} p<0.05$ versus Day 1.

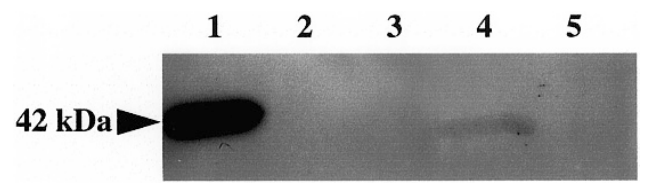

Figure 3.

Immunoblot analysis of smooth muscle $\alpha$-actin ( $\alpha$-SMA) expression in HSC after bile duct ligation. Immunoblot-ECL analysis of $\alpha$-SMA was performed in HSC after four passages in culture, used as a positive control (lane 1), in freshly isolated HSC from normal rats (lane 2), bile duct-ligated rats on postoperative Days 2 (lane 3) and 7 (lane 4), and in normal hepatocytes, used as a negative control (lane 5).

No PDGFR- $\beta$ surface protein was detected by flow cytometry in quiescent HSC isolated from shamoperated rats. The fluorescence signals resulting from the analysis of quiescent HSC were identical irrespective of whether the cells were incubated or not with the primary antibody. The signal obtained after incubation
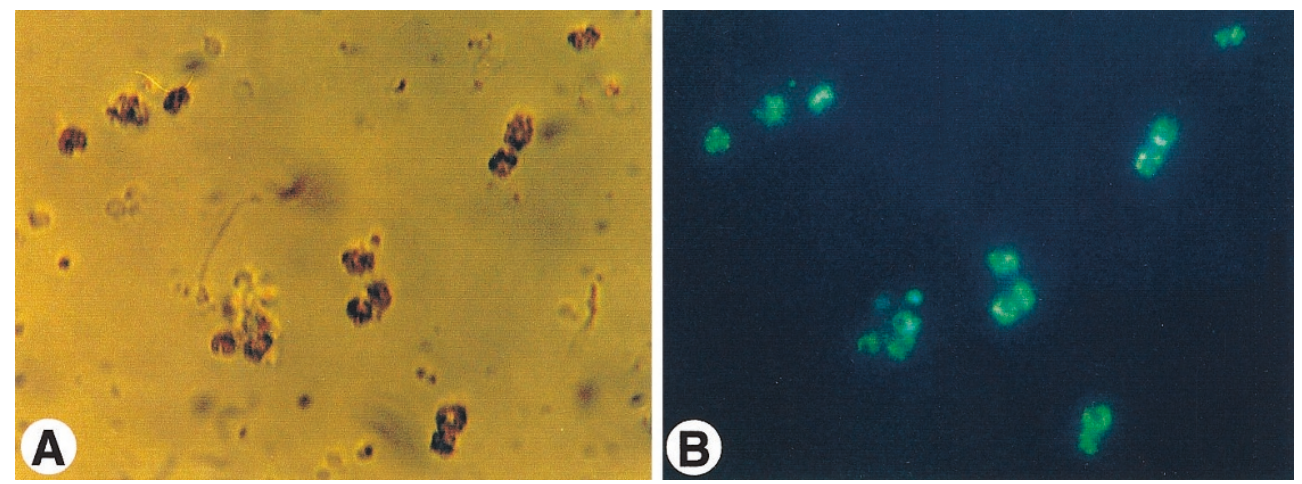

Figure 1.

Identification of freshly isolated hepatic stellate cells (HSC). Virtually all cells examined under light microscopy (A), immediately after cell isolation, exhibited characteristic autofluorescence under ultraviolet excitation at 328-nm wavelength (B). Original magnification, $\times 400$. 
with the primary antibody was indistinguishable in HSC isolated from bile duct-ligated and from shamoperated rats on postoperative Day 1 (Fig. 4). At later time points, the cells from bile duct-ligated rats yielded higher immunofluorescence signals than the cells from sham-operated rats (Fig. 4), indicating that PDGFR- $\beta$ protein expression was induced in HSC between 24 and 48 hours after BDL, coincident with the onset of proliferation.

This finding suggested that PDGF-receptor activation was a triggering event in HSC early proliferative response. To test this possibility, cell proliferation was reassessed after the administration of STI571 (formerly known as CGP 57148B), a protein-tyrosine kinase inhibitor that shows potent inhibition of PDGFmediated events (Buchdunger et al, 1996, 2000). In addition to being an inhibitor of PDGF receptor tyrosine kinase, STI571 shows potent inhibitory effects on the Abl nonreceptor and c-kit receptor tyrosine kinases, whereas other closely related kinases are not affected (Buchdunger et al, 1996, 2000). The inhibition of PDGF-induced proliferation of HSC by STI571 was first examined in a culture model. Culture-activated myofibroblastic HSC express high levels of PDGFR- $\beta$ and respond to PDGF-BB by intense proliferation. STI571 caused a dose-dependent inhibition of the proliferation induced by PDGF-BB (10 $\mu \mathrm{g} / \mathrm{L})$ in these cells, as reflected by DNA synthesis (Fig. 5A), metabolic activity (Fig. 5B), and direct cell count (Fig. 5C). At a concentration of $10 \mu \mathrm{mol} / \mathrm{L}, \mathrm{STI} 571$ completely blunted PDGF-BB-induced proliferation, whereas it did not affect cell morphology or viability as tested by erythrosin exclusion. To test the effect of PDGF receptor inhibition in vivo, bile duct-ligated rats were treated by daily intraperitoneal injections of STI571. The number of proliferating HSC 48 hours after BDL, as assessed by in vivo incorporation of BrdU, was reduced by $60 \%$ in animals treated with STI571, when compared with those treated with vehicle alone $(p<0.05)$ (Fig. 6).

We next examined whether the reduction in BrdU positive HSC, isolated from STI571-treated animals,

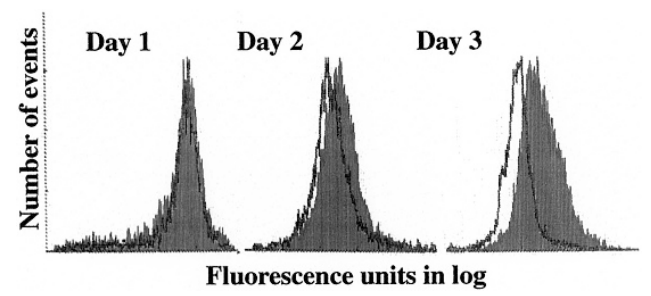

Figure 4.

Induction of platelet derived growth factor receptor $\beta$ (PDGFR- $\beta$ ) protein expression on the surface of HSC after BDL. HSC of high purity ( $\geq 99 \%)$, as illustrated in Figure 1, were isolated simultaneously from one sham-operated rat (open graphs) and one bile duct-ligated rat (filled graphs) on postoperative Days 1,2 , and 3 . PDGFR- $\beta$ protein was immunodetected on the surface of freshly isolated HSC by flow cytometry, using an antibody raised against the extracellular region of PDGFR- $\beta$. The fluorescence profiles of sham-operated rat cells and negative controls were identical. Superimposition of the graphs indicates that the expression of PDGFR- $\beta$ on the surface of HSC was induced between 24 and 48 hours after BDL. Each graph is representative of three separate experiments.
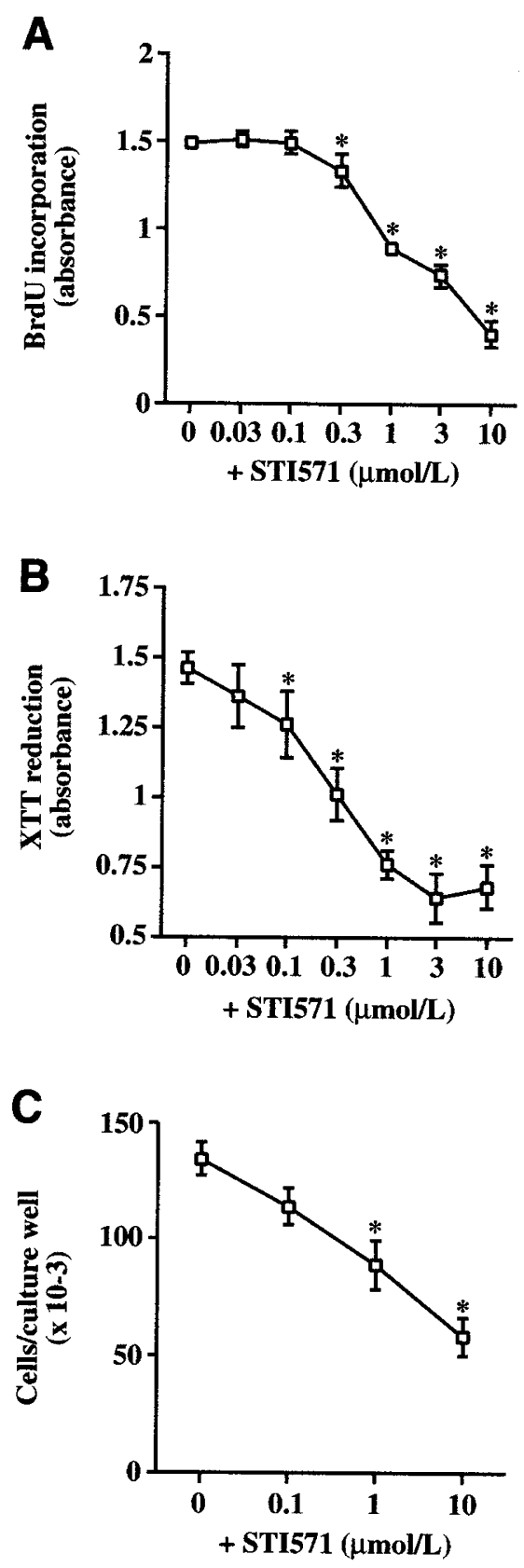

Figure 5.

Dose-dependent inhibition of PDGF-BB-induced proliferation by STI571 in culture-activated HSC. Growth arrest was achieved in culture-activated HSC between two and six passages by incubation in DME containing $0.5 \%$ serum and $0.2 \%$ BSA. The cells were then incubated for 96 hours in the same medium containing PDGF-BB $(10 \mu \mathrm{g} / \mathrm{L})$ and increasing concentrations $(0-10 \mu \mathrm{mo} / / \mathrm{L})$ of STI571, a PDGFR tyrosine kinase inhibitor. Cell proliferation was then assessed by (A) BrdU incorporation $(n=5)$, (B) XTT assay $(n=5)$, and (C) direct cell count $(n=3)$. Results are the means \pm SEM of experiments performed in triplicate. ${ }^{*} p<0.05$ versus PDGF-BB without STI571.

corresponded to a decrease in the number of desminimmunoreactive sinusoidal cells on liver tissue sections. The model of BDL causes a biliary type fibrosis originating in the portal tracts, which may involve cells other than HSC (Tang et al, 1994; Tuchweber et al, 1996). Portal tract cells were therefore excluded from the analysis and only sinusoidal cells were counted. Whereas the distribution of desmin immunolabeling in 


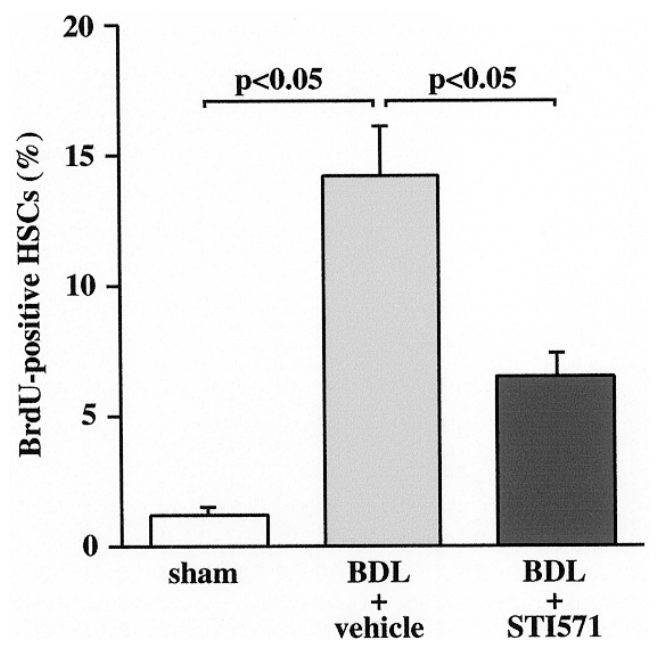

Figure 6.

Inhibition of HSC proliferation by STI571 in vivo. Daily intraperitoneal injections of STI571 (20 mg/kg) or of vehicle were started 1 day before BDL. HSC of high purity ( $\geq 99 \%$ ), as illustrated in Figure 1, were isolated simultaneously from one sham-operated rat, one vehicle-treated bile ductligated rat, and one STI571-treated bile duct-ligated rat on postoperative Day 2. One hour before cell isolation, each animal received an intraperitoneal injection of BrdU $(50 \mathrm{mg} / \mathrm{kg})$. BrdU was then immunodetected in freshly isolated HSC by flow cytometry. Results represent the percentage of BrdUpositive cells in each group and are the means \pm SEM of five separate experiments.

sham-operated rats was mainly confined to the wall of portal vessels and of terminal hepatic venules, with only occasional reactivity in sinusoids (Fig. 7A), a marked increase in immunoreactive cells within sinusoids was evident 48 hours after BDL (Fig. 7B). Treatment with STI571 caused a significant reduction in the number of desmin-immunoreactive cells in bile ductligated rats (Fig. 7C). The number of desmin-positive sinusoidal cells, 48 hours after BDL, was $5.2 \pm 0.54$ cells/high-power field in animals treated with STI571 as compared with $12.1 \pm 2.2$ cells/high-power field in those treated with vehicle alone $(p<0.05, n=5)$. In addition, the intensity of desmin immunolabeling was lower in treated bile duct-ligated rats than in untreated bile duct-ligated rats (Fig. 7, B and C).

\section{Discussion}

By analyzing the in vivo incorporation of BrdU in highly pure populations of HSC isolated at different time points after BDL, we herein provide the demonstration that liver injury elicits a very early proliferative response in HSC. HSC proliferation was induced and reached a plateau between 24 and 48 hours after BDL, before $\alpha$-SMA expression became detectable by immunoblot analysis of HSC. These results are compatible with those of earlier in situ studies, showing that desmin-positive cells undergo proliferation very soon after the initiation of liver injury (Geerts et al, 1991; Hines et al, 1993; Johnson et al, 1992), although it was recently stressed that the intermediate filament protein desmin may be expressed by other hepatic cells of the fibroblast lineage (Knittel et al, 1999a, 1999b).

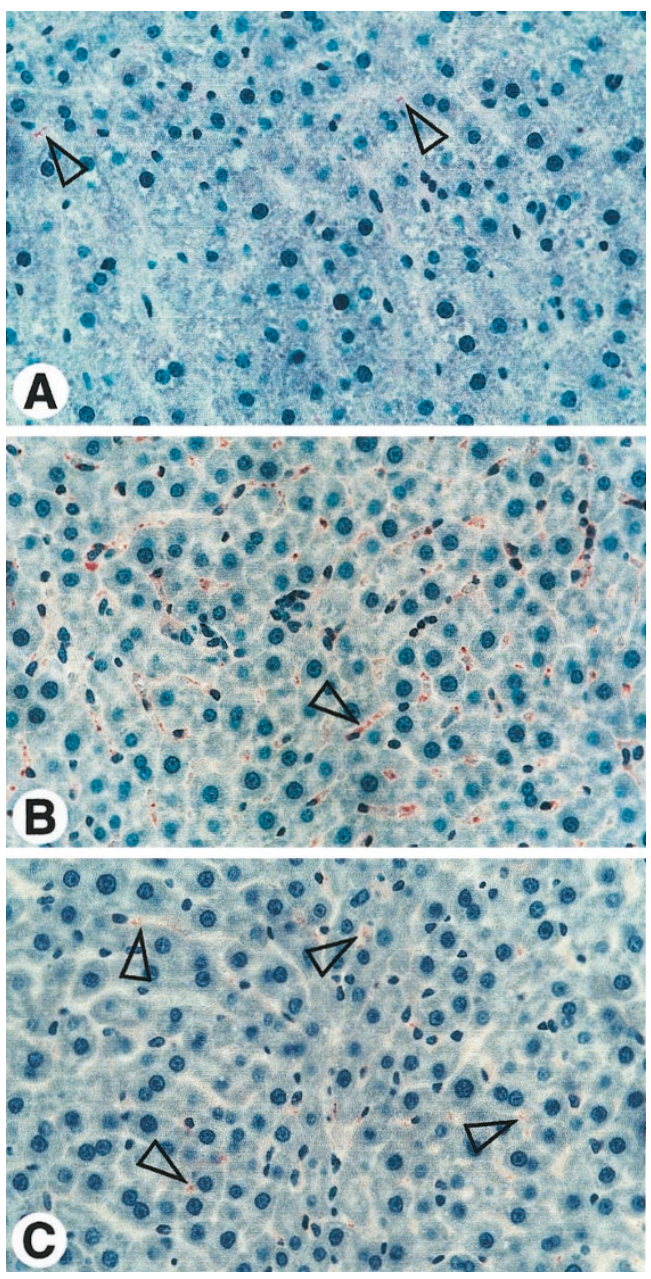

Figure 7.

Reduction in the amount of desmin-immunoreactive sinusoidal cells by STI571 in vivo. Daily intraperitoneal injections of STI571 $(20 \mathrm{mg} / \mathrm{kg})$ or vehicle were started 1 day before BDL. Desmin was detected by an indirect immunoperoxidase method on liver tissue sections from (A) sham-operated rats, $(B)$ vehicle treated bile duct-ligated rats, and (C) STI571-treated bile duct-ligated rats on postoperative Day 2. The immunolabeling of sinusoidal cells (open arrowheads), representative of five separate experiments, is shown. Original magnification, $\times 400$.

As previously noted in culture studies, the onset of HSC proliferation in vivo coincided with the acquisition of PDGFR- $\beta$. Only discrete induction of the protein was detected by flow cytometry and occurred within 48 hours after BDL. This was consistent with previous evidence that PDGFR- $\beta$ transcripts are induced within 8 hours after BDL, at levels that are relatively low, as compared with that induced by carbon tetrachloride administration (Wong et al, 1994). Because cell isolation requires protease treatment, the recovery of cell surface receptors was achieved by a 12-hour period of culture in suspension without serum. It was previously shown that PDGFR- $\beta$ mRNA remains undetectable in HSC up to 4 days of suspension culture, even in the presence of serum (Wong et al, 1994). We inferred from these studies that the up-regulation of PDGFR- $\beta$ in HSC was not influenced by the brief suspension culture. This was confirmed by the fact that PDGFR- $\beta$ 
was undetectable in HSC isolated from shamoperated rats.

When the PDGF receptor downstream signaling cascade was blocked by STI571 in bile duct-ligated rats (Buchdunger et al, 1996, 2000), HSC proliferation was inhibited by $60 \%$, providing the first evidence that PDGF acts as a potent mitogen for HSC in vivo. STI571 also shows inhibiting effects on c-kit (Buchdunger et al, 2000). However, the expression of c-kit in bile duct-ligated rat liver is restricted to bile duct epithelial cells (Fujio et al, 1996; Omori et al, 1997), making unlikely the possibility that HSC proliferation after cholestatic liver injury is mediated by c-kit. Because STI571 displays no specificity for either $\alpha$ or $\beta$ PDGFR subunits (Buchdunger et al, 2000), blocking experiments did not discriminate between the role of either PDGFR subtype in mediating PDGF mitogenic signals in HSC. However, the fact that PDGFR- $\alpha$ mRNA is not increased in HSC after liver injury (Wong et al, 1994), and that PDGF-AA does not elicit any proliferative response in HSC in vitro (Pinzani et al, 1991), suggests that PDGFR- $\beta$ induction is a triggering event in the HSC proliferative response. This possibility is supported by an earlier study showing that the activity of fibroblasts in the formation of connective tissue in vivo is remarkably sensitive to relatively small changes in PDGFR- $\beta$ expression levels (Crosby et al, 1999). Although STI571 caused complete inhibition of PDFG-BB induced proliferation in vitro, treatment with STI571 did not completely blunt HSC proliferation in vivo. One possible explanation would be that HSC were not accessible to optimal doses of STI571 in vivo. Another possibility is that the induction of HSC proliferation in liver injury depends upon additional growth factors such as endothelin-1, insulin-like growth factor 1, and transforming growth factor $\alpha$, which stimulate the proliferation of HSC in early culture (Bachem et al, 1993; Rockey et al, 1998).

It can be assumed that the anti-proliferative effect of STI571 on HSC partly accounts for the decreased number of desmin-positive sinusoidal cells in treated bile duct-ligated rats, in particular, because both BrdU incorporation in HSC and the number of desminimmunoreactive sinusoidal cells were reduced by approximately $60 \%$ in treated animals. STI571 not only caused a decrease in the number of desmin-positive cells but also in the intensity of desmin immunolabeling. In the present study, as noted before (Ballardini et al, 1988; Geerts et al, 1991), initial injury was accompanied by a marked increase in the intensity of sinusoidal desmin immunoreactivity, indicating that upregulation of desmin expression is an early feature of HSC activation. Because PDGF-BB has the ability to stimulate myofibroblastic differentiation in different cell types such as fibrocytes (Oh et al, 1998), the inhibitory effect of STI571 on desmin expression in bile duct-ligated rats may also be attributed to an inhibition of PDGF-mediated activation of HSC.

In summary, the present study shows that cholestatic liver injury elicits a very early proliferative response in HSC that is mainly mediated by PDGF and that precedes full conversion of HSC into myofibro- blasts. This early proliferative response of HSC may be part of a cascade of reversible events leading to hepatic wound healing. With ongoing or recurrent injury, HSC will eventually complete their transition into fibrogenic myofibroblasts responsible for the development of fibrosis. Early HSC proliferation may thus be regarded as an important defense mechanism aimed at delimiting injury and at promoting regeneration in the liver.

\section{Materials and Methods}

\section{Animal Model and In Vivo Procedures}

Liver injury was induced in male Sprague-Dawley rats weighing 450-550 g (R Janvier, Le Genest St Isle, France) by double ligation and scission of the common bile duct while under ether anesthesia (Kountouras et al, 1984). Sham operation consisted in laparotomy and exposure of the common bile duct. Bile duct-ligated and sham-operated rats were submitted to a concomitant schedule. All animals received humane care according to the criteria outlined in the Guide for the Care and Use of Laboratory Animals prepared by the National Academy of Sciences and published by the National Institutes of Health (Bethesda, Maryland). To assess HSC proliferation in vivo, BrdU from Roche Molecular Biochemicals (Mannheim, Germany) (50 $\mathrm{mg} / \mathrm{kg}$ ) in $0.9 \% \mathrm{NaCl}$ solution $(1 \mathrm{ml})$ was injected in the peritoneum, 1 hour before cell isolation. Inhibition of HSC proliferation by STI571, an inhibitor of PDGF receptor tyrosine kinase (provided by Dr. Elisabeth Buchdunger, Novartis Pharma Inc., Basel, Switzerland), was tested in bile duct-ligated rats (Buchdunger et al, 1996, 2000). Daily intraperitoneal injections of STI571 $(20 \mathrm{mg} / \mathrm{kg})$ dissolved in $\mathrm{Me}_{2} \mathrm{SO}$ and diluted $1 / 20$ ( $\mathrm{vol} / \mathrm{vol}$ ) in PBS began 1 day before BDL. Vehicle alone was injected in control bile duct-ligated rats and in sham-operated rats.

\section{Cell Isolation and Culture Procedures}

HSC were isolated by an established method (Friedman and Roll, 1987) with modifications (Kinnman et al, 2000). In brief, the liver was perfused in situ successively with $0.18 \%$ pronase and with $0.025 \%$ collagenase B (both from Roche Molecular Biochemicals). The liver cell suspension was incubated in $0.04 \%$ pronase and 6-mg/L deoxyribonuclease (Roche Molecular Biochemicals) under agitation. HSC were then separated by density gradient centrifugation through 8.2\% Nycodenz (Sigma, Saint-Quentin Fallavier, France). The purity of HSC isolates was higher than $99 \%$, as assessed by fluorescence of retinoidcontaining vacuoles under ultraviolet excitation (Friedman and Roll, 1987; Knook et al, 1982), and cell viability exceeded $90 \%$, as tested by erythrosin exclusion (Krause et al, 1984). HSC isolated from normal rats were grown on uncoated plastic in $75 \mathrm{~cm}^{2}$ flasks until confluency in DME (Sigma), containing $4 \mathrm{mmol} / \mathrm{L}$ L-Glutamine (GIBCO BRL, Life Technologies, CergyPontoise, France), 100,000 IU-100 mg/L penicillinstreptomycin (GIBCO BRL), 10\% fetal calf serum 
(GIBCO BRL), and 10\% horse serum (Sigma). The cells were maintained at $37^{\circ} \mathrm{C}$ under air/ $\mathrm{CO}_{2} 95 \% /$ $5 \%$. Medium was changed 24 hours after plating and every 48 hours, thereafter.

\section{Flow Cytometry}

Immunodetection of BrdU. After BrdU incorporation in vivo, HSC were isolated and immediately fixed in PBS containing 1\% paraformaldehyde (Sigma) for 18 hours. The cells were then permeabilized and their DNA content partially denatured, in a $0.9 \%-\mathrm{NaCl}$ solution containing 1\% Triton (Prolabo, Fontenaysous-Bois, France), $0.15 \%$ pepsin (Sigma), and 1 $\mathrm{mol} / \mathrm{L}$ chlorhydric acid (Prolabo). After centrifugation, HSC nuclei were incubated with an anti-BrdU mouse monoclonal antibody (Roche Molecular Biochemicals), diluted 1/50 in PBS containing 2\% BSA (Sigma) and $0.5 \%$ Tween 20 (Sigma), for 30 minutes at $4^{\circ} \mathrm{C}$. HSC nuclei were then washed and incubated with FITC-labeled goat anti-mouse IgG (Immunotech, Marseille, France), diluted $1 / 40$, for 30 minutes at $4^{\circ} \mathrm{C}$. HSC nuclei were finally washed and incubated with 10 $\mathrm{mg} / \mathrm{L}$ propidium iodide (Sigma) for 15 minutes and analyzed on an EPICS Elite flow cytometer (BeckmanCoulter, Villepinte, France) equipped with a $488 \mathrm{~nm}$ argon ion laser $(15 \mathrm{~mW})$. The following parameters were determined: (a) forward angle light scatter, (b) wide angle light scatter measured through a 488 bandpass interference filter, (c) green fluorescence of FITC, measured through a 525 bandpass interference filter, and (d) red fluorescence of propidium iodide, measured through a 620 bandpass interference filter. Ten thousand cells from each sample were analyzed. All signals were recorded in a linear mode, except for green fluorescence of FITC, which was recorded in a Log mode. Gates were placed on the scattergram to exclude debris and aggregates. Controls were obtained by performing intraperitoneal injections of $0.9 \%$ $\mathrm{NaCl}$ without $\mathrm{BrdU}$ or by omitting the primary antibody.

Immunodetection of PDGF-Receptor $\beta$. Immediately after cell isolation from sham-operated or bile duct-ligated rats, HSC were suspended at a concentration of $5.10^{5}$ cells $/ \mathrm{ml}$ in DME/Ham's F12 (1:1) mixture (Sigma), containing 1\% BSA, and were maintained in suspension under gentle agitation, in tefloncoated plates (Prolabo) for 12 hours at $37^{\circ} \mathrm{C}$, in air/ $\mathrm{CO}_{2}$ 95\%/5\%, as described (Friedman et al, 1994; Wong et al, 1994). During this brief suspension culture, the cells were allowed to recover surface receptors that were cleaved by the proteases used in the prior cell separation procedure. The cells were then incubated with rabbit polyclonal antibody raised against the extracellular region, amino acids 425 to 446 (Santa Cruz Biotechnology, Santa Cruz, California), diluted $1 / 100$ for 30 minutes at $4^{\circ} \mathrm{C}$, and subsequently with FITC-labeled goat anti-rabbit IgG (Immunotech), diluted $1 / 50$. The cells were finally incubated with propidium iodide $(5 \mathrm{mg} / \mathrm{L})$ for 15 minutes and were analyzed on an ATC 3000 flow cytometer, as indicated above. The primary antibody was omitted in negative controls.

\section{Immunoblot}

Immunoblot analysis of $\alpha$-SMA in HSC was performed as previously described (Rockey et al, 1998), with modifications. Immediately after cell isolation from normal or bile duct-ligated rats, HSC were washed in PBS and lysed in a solution composed of $50 \mathrm{mmol} / \mathrm{L}$ Tris- $\mathrm{HCl}, 0.5 \%$ sodium deoxycholate, $0.1 \%$ SDS, and $1 \%$ Triton. Identical amounts of protein extracts as determined by the Pierce Protein Assay (Interchim, Montluçon, France) were separated by electrophoresis through a $7.5 \%$ SDS polyacrylamide gel and then transferred to a nitrocellulose membrane (Hybond ECL; Amersham Pharmacia Biotech, Orsay, France). Blots were incubated overnight at $4^{\circ} \mathrm{C}$ in a blocking buffer containing $5 \%$ skim milk. Blots were then incubated with an anti- $\alpha$-SMA mouse monoclonal antibody (Sigma), diluted 1/2,000, for 2 hours at room temperature, and subsequently, with peroxidaseconjugated goat anti-mouse IgG (P.A.R.I.S., Compiègne, France), diluted $1 / 10,000$, for 1 hour at room temperature. Immunoreactivity was revealed by enhanced chemiluminescence using an ECL kit (Amersham Pharmacia Biotech, Les Ulis, France). Cultureactivated myofibroblastic HSC and hepatocytes, isolated from normal rats exactly as described (Kinnman et al, 2000), were used as positive and negative controls, respectively. The conditions were established in preliminary experiments to obtain a linear range of response for immunoblotting.

\section{In Vitro Proliferation Assays}

To test the inhibition of PDGF-induced proliferation by STI571 in vitro, a stock concentration of $10 \mathrm{mmol} / \mathrm{L}$ STI571 was prepared in $\mathrm{Me}_{2} \mathrm{SO}$ and stored at $-20^{\circ} \mathrm{C}$. Activated HSC between 2 and 6 passages were plated in 96 -well microtiter plates (3750 cells/well) or in 24-well culture plates $\left(7.5 \times 10^{4}\right.$ cells/well) and allowed to adhere overnight in DME containing 20\% serum ( $10 \%$ fetal calf $/ 10 \%$ horse). Growth arrest was then achieved by incubation in DME containing $0.5 \%$ serum $(0.25 \%$ fetal calf $/ 0.25 \%$ horse) and $0.2 \%$ BSA for 48 hours. Subsequently, the cells were incubated with PDGF-BB $(10 \mu \mathrm{g} / \mathrm{L})$ and increasing $(0-10 \mu \mathrm{mol} / \mathrm{L})$ concentrations of STI571 for 96 hours. Medium and additives were renewed after 48 hours. After a 96 -hour incubation, cell viability was appreciated by erythrosin exclusion and cell proliferation was assessed by three different methods. BrdU incorporation was used to measure DNA synthesis in a colorimetric immunoassay. Cells in 96-well microtiter plates were incubated with BrdU (BrdU kit, Roche Molecular Biochemicals) at a final concentration of $10 \mu \mathrm{mol} / \mathrm{L}$ for 2 hours. After cell fixation and DNA denaturation, a peroxidaseconjugated anti-BrdU monoclonal antibody was added. Color reaction was developed with tetramethylbenzidine and absorbance of the reaction product was measured at a $450-\mathrm{nm}$ wavelength in a scanning 
multiwell spectrophotometer (Amersham Pharmacia Biotech). Mitochondrial reduction of the tetrazolium salt XTT to formazan was used to appreciate the number of viable, metabolically active cells (Roehm et al, 1991). Cells in 96-well microtiter plates were incubated with $300 \mathrm{~g} / \mathrm{L}$ XTT (Roche Molecular Biochemicals) for 4 hours. Absorbance of the reaction product was measured at a 450-nm wavelength in a scanning multiwell spectrophotometer. Direct cell counting was performed in 24-well plates. The cells were harvested after trypsinization and then counted in a hemocytometer.

\section{Immunohistochemistry}

Desmin immunolabeling was performed on liver tissue sections from sham-operated rats, vehicle-treated bile duct-ligated rats, and STI571-treated bile duct-ligated rats. Four micrometer-thick tissue sections of formalin-fixed, paraffin-embedded liver tissue were submitted to a three-step immunoperoxidase method. Tissue sections were first incubated with an antidesmin mouse monoclonal antibody (Dako S.A., Trappes, France), diluted $1 / 20$, for 30 minutes at room temperature. Tissue sections were then incubated successively with peroxidase-conjugated, rabbit antimouse and swine anti-rabbit polyclonal antibodies (Dako S.A.) for 40 minutes at room temperature. Peroxidase activity was revealed by 3-amino-9ethylcarbazole (Vector Laboratories, Burlingame, CA). The slides were counterstained with Mayer's hematoxylin and mounted in Glycergel aqueous mounting medium (Dako S.A.). In negative controls the primary antibody was either omitted or replaced by irrelevant mouse antibodies (Dako S.A.). Desmin-labeled cells were counted using an eyepiece micrometer at high power $(\times 400)$ magnification. The average count in 10 random fields was used as a single score for each animal's liver.

\section{Statistical Analysis}

Data are presented as means \pm SEM. In the calculation of mean values and statistical variation, " $n$ " refers to the number of separate experiments. Differences between groups were analyzed by using the unpaired Student's $t$ test (two groups) or one-way ANOVA (multiple comparisons). $p<0.05$ was considered significant.

\section{Acknowledgements}

The authors wish to acknowledge Elisabeth Buchdunger (Novartis Pharma Inc., Basel, Switzerland) who provided STI571, Claire Francoz for help with immunoblot, and Michel Maratrat and François Ballet (Aventis, Centre de Recherche de Vitry-Alfortville, Vitry-surSeine, France) for helpful suggestions.

\section{References}

Bachem MG, Meyer D, Schafer W, Riess U, Melchior R, Sell KM, and Gressner AM (1993). The response of rat liver perisinusoidal lipocytes to polypeptide growth regulator changes with their transdifferentiation into myofibroblast-like cells in culture. J Hepatol 18:40-52.

Ballardini G, Fallani M, Biagini G, Bianchi FB, and Pisi E (1988). Desmin and actin in the identification of Ito cells and in monitoring their evolution to myofibroblasts in experimental liver fibrosis. Virchows Arch B Cell Pathol Incl Mol Pathol 56:45-49.

Buchdunger E, Cioffi CL, Law N, Stover D, Ohno-Jones S, Druker BJ, and Lydon NB (2000). Abl protein-tyrosine kinase inhibitor STI571 inhibits in vitro signal transduction mediated by C-Kit and platelet-derived growth factor receptors. J Pharmacol Exp Ther 295:139-145.

Buchdunger E, Zimmermann J, Mett H, Meyer T, Muller M, Druker BJ, and Lydon NB (1996). Inhibition of the Abl protein-tyrosine kinase in vitro and in vivo by a 2-phenylaminopyrimidine derivative. Cancer Res 56:100104.

Crosby JR, Tappan KA, Seifert RA, and Bowen-Pope DF (1999). Chimera analysis reveals that fibroblasts and endothelial cells require platelet-derived growth factor receptorbeta expression for participation in reactive connective tissue formation in adults but not during development. Am J Pathol 154:1315-1321.

Friedman SL (2000). Molecular regulation of hepatic fibrosis, an integrated cellular response to tissue injury. J Biol Chem 275:2247-2250.

Friedman SL and Roll FR (1987). Isolation and culture of hepatic lipocytes, Kupffer cells, and sinusoidal endothelial cells by density gradient centrifugation with Stractan. Anal Biochemistry 161:207-218.

Friedman SL, Yamasaki G, and Wong L (1994). Modulation of transforming growth factor beta receptors of rat lipocytes during the hepatic wound healing response. Enhanced binding and reduced gene expression accompany cellular activation in culture and in vivo. J Biol Chem 269:10551-10558.

Fujio K, Hu Z, Evarts RP, Marsden ER, Niu CH, and Thorgeirsson SS (1996). Coexpression of stem cell factor and c-kit in embryonic and adult liver. Exp Cell Res 224:243-250.

Geerts A, Lazou JM, De Bleser P, and Wisse E (1991). Tissue distribution, quantitation and proliferation kinetics of fatstoring cells in carbon tetrachloride-injured rat liver. Hepatology 13:1193-1202.

Hart CE, Forstrom JW, Kelly JD, Seifert RA, Smith RA, Ross R, Murray MJ, and Bowen-Pope DF (1988). Two classes of PDGF receptor recognize different isoforms of PDGF. Science 240:1529-1531.

Heldin CH, Backstrom G, Ostman A, Hammacher A, Ronnstrand L, Rubin K, Nister M, and Westermark B (1988). Binding of different dimeric forms of PDGF to human fibroblasts: Evidence for two separate receptor types. EMBO J 7:1387-1393.

Heldin CH and Westermark B (1990). Platelet-derived growth factor: Mechanism of action and possible in vivo function. Cell Regul 1:555-566.

Hines JE, Johnson SJ, and Burt AD (1993). In vivo responses of macrophages and perisinusoidal cells to cholestatic liver injury. Am J Pathol 142:511-518.

Johnson SJ, Hines JE, and Burt AD (1992). Immunolocalization of proliferating perisinusoidal cells in rat liver. Histochem J 24:67-72. 
Kinnman N, Hultcrantz R, Barbu V, Rey C, Wendum D, Poupon R, and Housset C (2000). PDGF-mediated chemoattraction of hepatic stellate cells by bile duct segments in cholestatic liver injury. Lab Invest 80:697-707.

Knittel T, Kobold D, Piscaglia F, Saile B, Neubauer K, Mehde M, Timpl R, and Ramadori G (1999a). Localization of liver myofibroblasts and hepatic stellate cells in normal and diseased rat livers: Distinct roles of (myo-)fibroblast subpopulations in hepatic tissue repair. Histochem Cell Biol 112:387401.

Knittel T, Kobold D, Saile B, Grundmann A, Neubauer K, Piscaglia F, and Ramadori G (1999b). Rat liver myofibroblasts and hepatic stellate cells: Different cell populations of the fibroblast lineage with fibrogenic potential. Gastroenterology 117:1205-1221.

Knook DL, Seffelaar AM, and de Leeuw AM (1982). Fatstoring cells of the rat liver. Their isolation and purification. Exp Cell Res 139:468-471.

Kountouras J, Billing BH, and Scheuer PJ (1984). Prolonged bile duct obstruction: A new experimental model for cirrhosis in the rat. $\mathrm{Br} J$ Exp Pathol 65:305-311.

Krause AW, Carley WW, and Webb WW (1984). Fluorescent erythrosin $B$ is preferable to trypan blue as a vital exclusion dye for mammalian cells in monolayer culture. J Histochem Cytochem 32:1084-1090.

Maher JJ and McGuire RF (1990). Extracellular matrix gene expression increases preferentially in rat lipocytes and sinusoidal endothelial cells during hepatic fibrosis in vivo. J Clin Invest 86:1641-1648.

Oh SJ, Kurz H, Christ B, and Wilting J (1998). Platelet-derived growth factor-B induces transformation of fibrocytes into spindle-shaped myofibroblasts in vivo. Histochem Cell Biol 109:349-357.

Omori M, Evarts RP, Omori N, Hu Z, Marsden ER, and Thorgeirsson SS (1997). Expression of alpha-fetoprotein and stem cell factor/c-kit system in bile duct ligated young rats. Hepatology 25:1115-1122.
Pinzani M, Gesualdo L, Sabbah GM, and Abboud HE (1989). Effects of platelet-derived growth factor and other polypeptide mitogens on DNA synthesis and growth of cultured rat liver fat-storing cells. J Clin Invest 84:1786-1793.

Pinzani M, Knauss TC, Pierce GF, Hsieh P, Kenney W, Dubyak GR, and Abboud HE (1991). Mitogenic signals for platelet-derived growth factor isoforms in liver fat-storing cells. Am J Physiol 260:C485-491.

Rockey DC, Boyles JK, Gabbiani G, and Friedman SL (1992). Rat hepatic lipocytes express smooth muscle actin upon activation in vivo and in culture. J Submicrosc Cytol Pathol 24:193-203.

Rockey DC, Fouassier L, Chung JJ, Carayon A, Vallee P, Rey $C$, and Housset C (1998). Cellular localization of endothelin-1 and increased production in liver injury in the rat: Potential for autocrine and paracrine effects on stellate cells. Hepatology 27:472-480.

Roehm NW, Rodgers GH, Hatfield SM, and Glasebrook AL (1991). An improved colorimetric assay for cell proliferation and viability utilizing the tetrazolium salt XTT. J Immunol Methods 142:257-265.

Tang L, Tanaka Y, Marumo F, and Sato C (1994). Phenotypic change in portal fibroblasts in biliary fibrosis. Liver 14:76-82.

Tuchweber B, Desmouliere A, Bochaton-Piallat ML, RubbiaBrandt L, and Gabbiani G (1996). Proliferation and phenotypic modulation of portal fibroblasts in the early stages of cholestatic fibrosis in the rat. Lab Invest 74:265-278.

Wong L, Yamasaki G, Johnson RJ, and Friedman SL (1994). Induction of $\beta$-platelet-derived growth factor receptor in rat hepatic lipocytes during cellular activation in vivo and in culture. J Clin Invest 94:1563-1569. 